\title{
Motor Neuron Diseases and Myopathies: Implications for Perioperative Management and Intensive Care
}

\author{
Tino Prell" and Julian Grosskreutz
}

\author{
Hans-Berger Department of Neurology, Friedrich-Schiller-University Hospital Jena, Erlanger Allee 101, D-07747 \\ Jena, Germany
}

\begin{abstract}
Motor neuron diseases like amyotrophic lateral sclerosis and myopathies are associated with a higher risk of cardiac and respiratory complications, especially during operative procedures. This review gives an overview of the various complications from which patients with motor neurone diseases and muscular dystrophies may suffer during operations and anaesthesia. The main focus is on the pathophysiological aspects as well as the diagnoses of typical cardiac and respiratory complications, their prevention, and their management.
\end{abstract}

Keywords: Neuromuscular disease, respiratory failure, cardiac involvement, amyotrophic lateral sclerosis, muscular dystrophies, non-invasive ventilation, intensive care.

\section{INTRODUCTION}

Neuromuscular diseases are often associated with respiratory or cardiac problems. Based on the pathophysiological aspects neuromuscular diseases can be divided into the following main groups: First, neuropathies and motor neuron diseases (MND) which predispose to respiratory complications. Second, diseases of the neuromuscular junction, and third, muscular dystrophies (MD) with a high risk of cardiac and respiratory impairment. Disorders of the neuromuscular junction and their implications in intensive care medicine are discussed elsewhere in this volume. Fourth, peripheral neuropathies with mainly cardiac restrictions and autonomous dysregulation. And fifth, myopathies caused by endocrine, metabolic or inflammatory mechanisms. In this paper the pathophysiology, the diagnosis and management of respiratory and cardiac failure in patients with MND, MD, and myotonic dystrophies (DM) are described.

\section{PATHOPHYSIOLOGICAL ASPECTS OF RESPIRA- TORY AND CARDIAC FAILURE}

Respiratory muscle weakness is common in neuromuscular diseases. A weakness of the main inspiratory muscles the diaphragm and the chest wall muscles - causes orthopnea, paradoxical abdominal movement, and reduced vital capacity (VC). This results in a collapse of the peripheral small alveoli and the development of microatelectasis. A weakness of the main expiratory muscles - the abdominal muscles - can be recognized by a reduced maximal expiratory pressure and a reduced ability to cough [1]. An involvement of bulbar muscles can be noted by stridor, impaired swallowing and aspiration. The combination of restrictive ventilation failure and decreased peak cough flow with the inability to clear secretion causes a development of

*Address correspondence to this author at the Department of Neurology, Friedrich-Schiller-University Jena, Erlanger Allee 101, D-07747 Jena, Germany; Tel: ++49 +3641 9323459; Fax: ++49 +3641 9322267;

E-mail: tino.prell@med.uni-jena.de intrapulmonary shunts, hypoxia and at the end a respiratory muscle fatigue with hypercapnic respiratory failure [2] (Fig. 1).

Cardiac involvement has been documented in many MD. It manifests within the myocardium (e.g. in a case of dilated cardiomyopathy) or the cardiac conduction system resulting in arrhythmias and conduction defects. Exact clinical data regarding cardiac involvement are available for Duchenne/Becker MD, Emery-Dreifuss MD, limb-girdle MD, congenital MD and DM [3,4]. However, one should take into account that there is not necessarily a direct correlation between the extent of skeletal and cardiac involvement [5].

\section{DIAGNOSTIC ASSESSMENTS}

\section{Respiratory Investigations}

Patients suffering of respiratory muscle weakness can have the following complaints: dyspnea, sleep disturbance, daytime tiredness, headaches, poor concentration and mood changes. These symptoms are usually a consequence of hypoventilation, hypoxia and hypercapnia during sleep. Important investigations to assess the respiratory function in patients with neuromuscular diseases are the forced vital capacity (FVC), the sniff nasal inspiratory pressure (SNIP), the peak cough flow (PCF), the arterial blood gases and finally chest X-ray and overnight monitoring [6] (Table 1).

Table 1. Essential Assessments of Respiratory Function in Neuromuscular Disorders

- Ask for symptoms of hypercapnia (sleep disturbance, daytime tiredness, headache, poor concentration, mood changes)

- $\quad \mathrm{VC}$ and SNIP

- blood gases analysis

However, in patients with bulbar impairment, who cannot perform the pulmonary test exactly, the $\mathrm{VC}$ has serious limitations and underestimates respiratory function. A VC which is $25 \%$ lower in a lying than in a sitting/standing position 


\begin{tabular}{|c|c|c|}
\hline $\begin{array}{c}\text { Impaired ventilation } \\
\text { (weakness of inspiratory muscles) }\end{array}$ & $\begin{array}{c}\text { Inability to cough } \\
\text { (weakness of expiratory muscles } \\
\text { and upper airway muscles) }\end{array}$ & Upper airway obstruction \\
\hline & $\begin{array}{c}\text { atelectasis, secretion accumulation, } \\
\text { hypoxia, hypercapnia }\end{array}$ & \\
\hline
\end{tabular}

Fig. (1). Mechanism of respiratory failure in neuromuscular diseases.

strongly predicts diaphragm weakness [7]. More invasive methods (e.g. sniff trans-diaphragmatic pressure or diaphragm electromyography) are usually not practical in routine use.

\section{Cardiac Investigation}

In order to prevent sudden death and optimize morbidity, the screening for cardiac involvement becomes more and more important, but has to match the specific neuromuscular disease. In general, patients should undergo a cardiac investigation with an echocardiogram (Echo), an electrocardiogram (ECG) and a Holter monitor. Guidelines for the cardiac screening and the common cardiac involvements in MD and DM are shown in Table $2[3,8]$.

\section{SPECIAL ISSUES IN NEUROMUSCULAR DISEASES}

\section{Amyotrophic Lateral Sclerosis and Spinal Muscular Atrophy Type IV}

Amyotrophic lateral sclerosis (ALS) is a progressive neurodegenerative disease of the upper and lower motoneurons. Lower motoneuron destruction results in muscle weakness, fasciculations and atrophy. Clinical signs of upper motoneuron destruction are hyperreflexia and spasticity. A bulbar involvement is attended by dysphagia and dysarthria. Spinal muscular atrophy (SMA) type IV is an autosomal recessive disorder of the lower motoneuron. The clinical manifestations are symmetric muscle weakness with an accentuation of proximal muscles and the lower extremities.

A high percentage of ALS patients have obstructive, central and mixed sleep hypoventilation and apneas [9]. They usually die from hypercapnic respiratory failure or respiratory complications like aspiration pneumonia $[10,11]$. Thus a respiratory support by using non-invasive ventilation (NIV) (commonly bi-level positive airway pressure devices Bipap) is established to improve survival [12] and quality of life [13]. Criteria proposed for the initiation of a NIV were established by the European ALS/MND Consortium and European Neuromuscular Centre workshop on non-invasive ventilation in MND, 2002 [14, 15].

Table 2. Screening for Cardiac Involvement $[3,8]$

\begin{tabular}{|c|c|c|c|c|}
\hline & \multirow{2}{*}{ Cardiac Involvement } & \multicolumn{3}{|c|}{ Cardiac Screening } \\
\hline & & ECG & Echo & Holter Monitor \\
\hline $\begin{array}{l}\text { Duchenne MD - } \\
\text { Patients }\end{array}$ & $\begin{array}{l}\text { asymptomatic regional wall } \\
\text { motion abnormalities with the } \\
\text { posterobasal and lateral walls } \\
\text { of the left ventricle most } \\
\text { commonly affected, left } \\
\text { ventricular systolic } \\
\text { dysfunction, asymptomatic } \\
\text { ECG changes, } \\
\text { ventricular arrhythmias }\end{array}$ & $\begin{array}{l}\text { at diagnosis } \\
\text { before any surgery } \\
\text { every } 2 \text { year } \\
\text { to the age } 10 \\
\text { annually after the age } 10\end{array}$ & $\begin{array}{l}\text { at diagnosis } \\
\text { before any surgery } \\
\text { every } 2 \text { year to the age } 10 \\
\text { annually after } \\
\text { the age } 10\end{array}$ & \\
\hline $\begin{array}{l}\text { Duchenne MD - } \\
\text { Carriers }\end{array}$ & $\begin{array}{l}\text { ECG changes and dilated } \\
\text { cardiomyopathy }\end{array}$ & $\begin{array}{l}\text { at diagnosis } \\
\text { every } 5 \text { years }\end{array}$ & $\begin{array}{l}\text { at diagnosis } \\
\text { every } 5 \text { years }\end{array}$ & \\
\hline Becker MD & $\begin{array}{l}\text { myocardial damage of lateral and } \\
\text { posterior wall, dilated cardiomyopathy, } \\
\text { mitral regurgitation, ECG changes }\end{array}$ & $\begin{array}{l}\text { at diagnosis } \\
\text { every } 5 \text { years }\end{array}$ & $\begin{array}{l}\text { at diagnosis } \\
\text { every } 5 \text { years }\end{array}$ & \\
\hline $\begin{array}{l}\text { Emery-Dreifuss } \\
\text { MD } \\
\text { X-linked }\end{array}$ & $\begin{array}{c}\text { atrioventricular conduction } \\
\text { defects and atrial arrhythmias, } \\
\text { less common are cardiomyopathic } \\
\text { changes }\end{array}$ & $\begin{array}{l}\text { at diagnosis } \\
\text { annually }\end{array}$ & $\begin{array}{l}\text { on a less } \\
\text { regular basis }\end{array}$ & $\begin{array}{l}\text { at diagnosis } \\
\text { annually }\end{array}$ \\
\hline $\begin{array}{l}\text { Emery-Dreifuss MD } \\
\text { autosomal } \\
\text { dominant }\end{array}$ & $\begin{array}{l}\text { left ventricular involvement, } \\
\text { asymptomatic sinus } \\
\text { node or AV node disease }\end{array}$ & $\begin{array}{l}\text { at diagnosis } \\
\text { annually }\end{array}$ & $\begin{array}{l}\text { on a less } \\
\text { regular basis }\end{array}$ & $\begin{array}{l}\text { at diagnosis } \\
\text { annually }\end{array}$ \\
\hline $\begin{array}{l}\mathrm{DM} \\
\text { type } 1\end{array}$ & $\begin{array}{l}\text { Supraventricular arrhythmias, ventricular } \\
\text { arrhythmias, Bundle branch block } \\
\text { re-entry ventricular tachycardia }\end{array}$ & $\begin{array}{l}\text { at diagnosis } \\
\text { annually }\end{array}$ & $\begin{array}{l}\text { at diagnosis } \\
\text { every } 5 \text { years }\end{array}$ & $\begin{array}{c}\text { at diagnosis and } \\
\text { if annual ECG shows } \\
\text { increasing PR interval or other } \\
\text { evidence of increased risk } \\
\text { of bradycardia }\end{array}$ \\
\hline
\end{tabular}


Respiratory infections in SMA or ALS are an important problem because of the combination of muscle weakness and increased airway secretions. A treatment should aim at normalising the gas exchange by reducing both atelectasis and the secretion accumulation. Following an antibiotic therapy, if necessary, the first intervention is manual and mechanical cough assist $[16,17]$. Bipap decreases respiratory muscular work and improves gas exchange and should be considered early during an acute illness [18]. The administration of oxygen is not a first-line therapy, but should be used if the hypoxemia continues and after airway clearance and NIV is maximized [17]. In general, the American College of Chest Physicians recommends chest physiotherapy, manually assisted cough, expiratory muscle training, the administration of positive expiratory pressure from 5 to $20 \mathrm{~cm} \mathrm{H}_{2} \mathrm{O}$ delivered by facemask, and mechanical cough assist devices for patients with neuromuscular diseases, although the effect of non-pharmacologic airway clearance techniques on long-term outcomes is unknown at the moment [16].

Additionally, dysphagia is a common problem in ALS and leads to aspiration, weight loss and dehydration [19]. Because gastrostomy is one of the most frequent operations in ALS patients, some special aspects should be mentioned. Most authors consider gastrostomy when the body weight loss is greater than $10 \%$ of the pre-diagnostic or baseline weight and in cases of difficulty swallowing with evidence of aspiration [16, 20]. There are three options for gastrostomy: a percutaneous endoscopic gastrostomy (PEG), a radiologically inserted gastrostomy and a nasogastric tube. Because it requires mild sedation, PEG could impair respiratory function in patients with respiratory weakness. Therefore PEG should be done as long as VC $>50 \%$, SNP $>$ $40 \mathrm{H}_{2} \mathrm{O}$ and morning blood gases are normal $[15,21]$. In cases of respiratory insufficiency (VC $<50 \%$, SNIP $<40$ $\mathrm{H}_{2} \mathrm{O}$ etc.) a NIV should be tried before and if necessary after a gastrostomy to avoid pulmonary insufficiency and intubation. A sufficient analgetic therapy after the application of PEG to minimize pain induced diaphragm atony is essential to minimize complications.

Anaesthetic complications are also common in ALS and SMA. In addition to respiratory dysfunction and risk of aspiration there is a pathologic reaction to muscle relaxants. Depolarising muscle relaxants are contraindicated. They can cause myotonia-like contractions (e.g. masseter spasm), resulting in difficulty to intubate, and rhabdomyolysis with severe hyperkalaemia and consecutive renal failure or cardiac complications such as arrhythmias [22, 23]. The sensitivity of non-depolarising muscle relaxants is increased, therefore the dose should be reduced in patients with ALS [24].

\section{Duchenne and Becker MD}

The Duchenne MD is an X-linked recessive myopathy with dystrophin loss that presents in childhood with progressive loss of muscle strength and gait disturbance. Developing scoliosis and changes in thoracic anatomy contribute to a restrictive ventilatory defect approximately after 10 years and a muscular weakness of the diaphragm is followed by hypoventilation and in $80 \%$ of cases by death secondary to respiratory failure [2]. Becker MD is caused by reduced levels or abnormal variants of dystrophin. The age of onset of the muscle weakness is variable and normally later than in Duchenne MD.

Using the respiratory assessments described above patients undergoing general anaesthesia with a preoperative FVC $<50 \%$ of that predicted are at increased risk of complications and if the preoperative FVC value is $<30 \%$ of that predicted they are at high risk for complications. To optimize the success of postoperative extubation facilitated by NIV a preoperative and a postoperative NIV is recommended for patients at increased risk and is necessary for patients at high risk. For patients with a reduced ability to cough (PCF $<2701 / \mathrm{min})$ a preoperative training and postoperative use of manual/mechanical assisted cough is advised [25].

As mentioned above, a cardiac involvement (left ventricular failure, arrhythmia) is common and does not correlate with the degree of skeletal involvement [5]. It increases with age and is found in almost all patients older than 18 years. Thus the anaesthetic risks are determined by the respiratory and cardiac functions. Depolarising muscle relaxants and volatile anaesthetics have a high risk of hyperkalaemia induced cardiac arrest, malignant hyperthermia-like episodes and rhabdomyolysis [26]. It is important to monitor the volume status of patients with Duchenne MD because hypovolaemia often leads to cardiac decompensation, cognizable as tachycardia worsened by hypovolaemia [24].

\section{Myotonic Dystrophy}

DM is a progressive, autosomal dominant multisystemic disease characterized by muscular dystrophy with muscle weakness, myotonia (delayed relaxation of skeletal muscle), cataract, diabetes mellitus and cardiac symptoms. The myotonic dystrophy type 1 (DM1) can present at any age, including infancy, with a high risk of death in the neonatal period. Limb weakness begins distally in the extremities and can slowly progress to proximal muscles. Most patients with the myotonic dystrophy type 2 (DM2) become symptomatic between the ages of 20 and 60 years; initial there is usually an intermittent stiffness and pain of the proximal muscles in one or both legs (PROMM or proximal myotonic myopathy). A cardiac involvement is common especially in type 1 and manifests itself in supraventricular flutter and fibrillation as well as ventricular arrhythmias. Pacemakers can extend life expectancy and are indicated for a third grade AV-block at any anatomical level and advanced second grade AV-block [27]. Regarding anaesthetic issues one has to keep in mind that depolarising muscle relaxants and cholinesterase inhibitors are contraindicated. They can aggravate myotonic muscle reactions followed by problems with intubation and ventilation [28]. Also coldness or postoperative shivering as triggers for myotonic reactions should be avoided. Affected smooth muscles (oesophagus, stomach) increase the previously existing risk of aspiration [24]. Moreover, respiratory depressant drugs can lead to prolonged phases of apnoea in patients with myotonic dystrophy.

\section{CONCLUSION}

Cardiac involvement and respiratory failure are common in neuromuscular diseases and frequently result in reduced 
life expectancy. The pathophysiological mechanism of respiratory failure is a combination of impaired ventilation, the inability to cough and upper airway obstruction, resulting in a high risk of aspiration, atelectasis and hypoxia. Regular and solid cardiac and pulmonic investigations are essential to predict and avoid complications during operations, anaesthesia and acute illness. In cases of respiratory failure, NIV as well as non-pharmacologic airway clearance techniques should be considered early during treatment.

\section{ABBREVIATIONS}

$$
\begin{aligned}
& \text { ALS }=\text { Amyotrophic lateral sclerosis } \\
& \text { AV }=\text { Atrioventricular } \\
& \text { Bipap }=\text { Bi-level positive airway pressure devices } \\
& \text { DM }=\text { Myotonic dystrophy } \\
& \text { ECG }=\text { Electrocardiogram } \\
& \text { Echo }=\text { Echocardiogram } \\
& \text { FVC }=\text { Forced vital capacity } \\
& \text { MD }=\text { Muscular dystrophies } \\
& \text { MND }=\text { Motor neurone disease } \\
& \text { NMD }=\text { Neuromuscular diseases } \\
& \text { NIV }=\text { Non-invasive ventilation } \\
& \text { PCF }=\text { Peak cough flow } \\
& \text { PEG }=\text { Percutaneous endoscopic gastrostomy } \\
& \text { SNIP }=\text { Sniff nasal inspiratory pressure } \\
& \text { VC }=\text { Vital capacity }
\end{aligned}
$$

\section{REFERENCES}

[1] MacDuff A, Grant IS. Critical care management of neuromuscular disease, including long-term ventilation. Curr Opin Crit Care 2003; 9(2): 106-12.

[2] Vazquez-Sandoval A, Huang EJ, Jones SF. Hypoventilation in neuromuscular disease. Semin Respir Crit Care Med 2009; 30(3): 348-58.

[3] Beynon RP, Ray SG. Cardiac involvement in muscular dystrophies. QJM 2008; 101(5): 337-44.

[4] Perrot A, Spuler S, Geier C, Dietz R, Osterziel KJ. Cardiac manifestations of muscular dystrophies. Z Kardiol 2005; 94(5): 312-20

[5] Melacini P, Vianello A, Villanova C, et al. Cardiac and respiratory involvement in advanced stage Duchenne muscular dystrophy. Neuromuscul Disord 1996; 6(5): 367-76.

[6] Leigh PN, Abrahams S, Al-Chalabi A, et al. The management of motor neurone disease. J Neurol Neurosurg Psychiatry 2003; 74(4): $32-47$

[7] Lechtzin N, Wiener CM, Shade DM, Clawson L, Diette GB. Spirometry in the supine position improves the detection of diaphragmatic weakness in patients with amyotrophic lateral sclerosis. Chest 2002; 121: 436-42.

[8] Bushby K, Muntoni F, Bourke JP. 107 ${ }^{\text {th }}$ ENMC international workshop: the management of cardiac involvement in muscular dystrophy and myotonic dystrophy. $7^{\text {th }}-9^{\text {th }}$ June 2002 , Naarden, the Netherlands. Neuromuscul Disord 2003; 13(2): 166-72.

[9] Atalaia A, De Carvalho M, Evangelista T, Pinto A. Sleep characteristics of amyotrophic lateral sclerosis in patients with preserved diaphragmatic function. Amyotroph Lateral Scler 2007; 8(2): 101-5.

[10] Kaplan LM, Hollander D. Respiratory dysfunction in amyotrophic lateral sclerosis. Clin Chest Med 1994; 15(4): 675-81.

[11] Shimizu T, Hayashi H, Kato S, Hayashi M, Tanabe H, Oda M. Circulatory collapse and sudden death in respirator-dependent amyotrophic lateral sclerosis. J Neurol Sci 1994; 124(1): 45-55.

[12] Kleopa KA, Sherman M, Neal B, Romano GJ, Heiman-Patterson T. Bipap improves survival and rate of pulmonary function decline in patients with ALS. J Neurol Sci 1999; 164(1): 82-8.

[13] McDonald ER, Hillel A, Wiedenfeld SA. Evaluation of the psychological status of ventilatory-supported patients with ALS/MND. Palliat Med 1996; 10(1): 35-41.

[14] Andersen PM, Borasio GD, Dengler R, et al. Good practice in the management of amyotrophic lateral sclerosis: clinical guidelines. An evidence-based review with good practice points. EALSC Working Group. Amyotroph Lateral Scler 2007; 8: 195-213.

[15] Mathus-Vliegen LM, Louwerse LS, Merkus MP, Tytgat GN, Vianney de Jong JM. Percutaneous endoscopic gastrostomy in patients with ALS and impaired pulmonary function. Gastrointest Endosc 1994; 40: 463-9.

[16] McCool FD, Rosen MJ. Nonpharmacologic airway clearance therapies: ACCP evidence-based clinical practice guidelines. Chest 2006; 129(1): 250-9.

[17] Schroth MK. Special considerations in the respiratory management of spinal muscular atrophy. Pediatrics 2009; 123(4): 245-9.

[18] Mehta S, Hill NS. Noninvasive ventilation. Am J Respir Crit Care Med 2001; 163(2): 540-77.

[19] Kasarskis EJ, Berryman S, Vanderleest JG, et al. Nutritional status of patients with ALS: relation of the proximity of death. Am J Clin Nutr 1996; 63: 130-7.

[20] Wijesekera LC, Leigh PN. Amyotrophic lateral sclerosis. Orphanet J Rare Dis 2009; 4: 3.

[21] Mazzini L, Corrà T, Zaccala M, Mora G, Del Piano M, Galante M. Percutaneous endoscopic gastrostomy and enteral nutrition in ALS. J Neurol 1995; 242: 695-8.

[22] Beach TP, Stone WA, Hamelberg W. Circulatory collapse following succinylcholine: report of a patient with diffuse lower motor neuron disease. Anesth Analg 1971; 50(3): 431-7.

[23] Cooperman LH. Succinylcholine-induced hyperkalemia in neuromuscular disease. JAMA 1970; 213(11): 1867-71.

[24] Klingler W, Lehmann-Horn F, Jurkat-Rott K. Complications of anaesthesia in neuromuscular disorders. Neuromuscul Disord 2005; 15(3): 195-206.

[25] Birnkrant DJ. The American College of Chest Physicians consensus statement on the respiratory and related management of patients with Duchenne muscular dystrophy undergoing anesthesia or sedation. Pediatrics 2009; 123(4): 242-4.

[26] Breucking E, Reimnitz P, Schara U, Mortier W. Anesthetic complications. The incidence of severe anesthetic complications in patients and families with progressive muscular dystrophy of the Duchenne and Becker types. Anaesthesist. 2000; 49(3): 187-95.

[27] Gregoratos G, Abrams J, Epstein AE, et al. American College of Cardiology/American Heart Association Task Force on Practice Guidelines/North American Society for Pacing and Electrophysiology Committee to Update the 1998 Pacemaker Guidelines. ACC/AHA/NASPE 2002 guideline update for implantation of cardiac pacemakers and antiarrhythmia devices: summary article: a report of the American College of Cardiology/American Heart Association Task Force on Practice Guidelines (ACC/AHA/ NASPE Committee to Update the 1998 Pacemaker Guidelines). Circulation 2002; 106(16): 2145-61

[28] Baur CP, Schara U, Schlecht R, Georgieff M, Lehmann-Horn F. Anesthesia in neuromuscular disorders. Part 2: specific disorders. Anasthesiol Intensivmed Notfallmed Schmerzther 2002; 37(3): 125-37. 